\title{
Synthesis, structural and mechanical characterization of sputtered tungsten oxide coatings
}

\author{
N.M.G. Parreira *, N.J.M. Carvalho, A. Cavaleiro \\ ICEMS-Grupo de Materiais e Engenharia de Superficies, Faculdade de Ciências e Tecnologia da Universidade de Coimbra-Pólo II, \\ 3030-201 Coimbra, Portugal
}

Received 15 June 2005; received in revised form 19 December 2005; accepted 19 December 2005

Available online 7 February 2006

\begin{abstract}
Tungsten oxide coatings were deposited without substrate bias by DC reactive magnetron sputtering of a tungsten target using oxygen as reactive gas. By tuning the partial pressure of oxygen $\left(p_{\mathrm{O}_{2}} / p_{\mathrm{Ar}}\right)$ between 0 and 4 , the oxygen content of the films was changed from 0 to 75 at.\%. The structure of the films (investigated by X-ray diffraction) depends on their oxygen content. For low oxygen contents, the $\alpha$-W and $\beta$ $\mathrm{W}_{3} \mathrm{O}$ phases were observed $(<30$ at. $\%)$, and with the increase of oxygen content $(30$ at. $\%<0<67$ at. $\%$ ) the structure became amorphous. A transition region was obtained for oxygen content between 67 at.\% and 75 at.\%, and when $\mathrm{O}>75$ at.\%, a nanocrystalline $\left(\mathrm{WO}_{3}\right)$ structure was reached.

The hardness and Young's modulus were evaluated by depth sensing indentation. The decrease in hardness followed the four different ranges of chemical compositions accordingly, from $\approx 23 \mathrm{GPa}$ for pure $\mathrm{W}$ down to $\approx 7 \mathrm{GPa}$ for $\mathrm{WO}_{3}$ films. A similar behaviour was observed for the Young's modulus, which ranged from $450 \mathrm{GPa}$ to $150 \mathrm{GPa}$. The cohesion/adhesion of the films were investigated using a scratch-test apparatus. These coatings displayed a low adhesion (critical load, $L_{\mathrm{c}}<15 \mathrm{~N}$ ) to the steel substrate because the depositions were carried out intentionally without an adhesion interfacial layer.
\end{abstract}

(C) 2005 Elsevier B.V. All rights reserved.

Keywords: Tungsten oxide; Reactive sputtering; Structural properties; Mechanical properties

\section{Introduction}

Tungsten oxides were studied in the past due to their electrooptical properties (e.g. exhibit electrochromic behaviour) [1] and, more recently, due to their applications in gas sensor devices [2]. These studies were focus to the stoichiometric compound $\mathrm{WO}_{3}$ or $\mathrm{WO}_{3-x}(x=0-1)$. However, works concerning all full range of compositions between pure tungsten to tungsten trioxide $\left(\mathrm{WO}_{3}\right)$ are not common in the literature. Only recently, Yamamoto et al. [3] have studied the electrical and optical properties of $\mathrm{W}-\mathrm{O}$ coatings deposited by radio frequency $(\mathrm{RF})$ reactive magnetron sputtering. Moreover, according Lugscheider et al. [4], these coatings have good

\footnotetext{
* Corresponding author. Tel.: +351 239790 745; fax: +351 239790701

E-mail addresses: nuno.parreira@dem.uc.pt (N.M.G. Parreira), nuno.carvalho@dem.uc.pt (N.J.M. Carvalho), albano.cavaleiro@dem.uc.pt (A. Cavaleiro).
}

tribological properties, but their mechanical properties were not characterized yet.

Several methods have been used to produce tungsten oxide including evaporation, sol-gel, chemical vapour deposition, RF sputtering and direct current (DC) reactive magnetron sputtering [5]. In this work, DC reactive magnetron sputtering was used because it is one of the most versatile techniques to produce new compounds with a wide range of chemical composition. By a simple control of the partial pressure of the reactive gas in the deposition chamber, it is possible to deposit coatings with a wide range of composition and, consequently, different properties. Nevertheless, with this technique, it is necessary to prevent the occurrence of poisoning of the target that occurs by the formation of a compound layer on its surface [6]. The phenomenon is accompanied by a great reduction of the sputtering rate.

This work is included as a vast project where a study of new oxynitride materials based on tungsten is performed. The main objective of this paper was to study the deposition process of the $\mathrm{W}-\mathrm{O}$ system where the chemical composition ranged from 


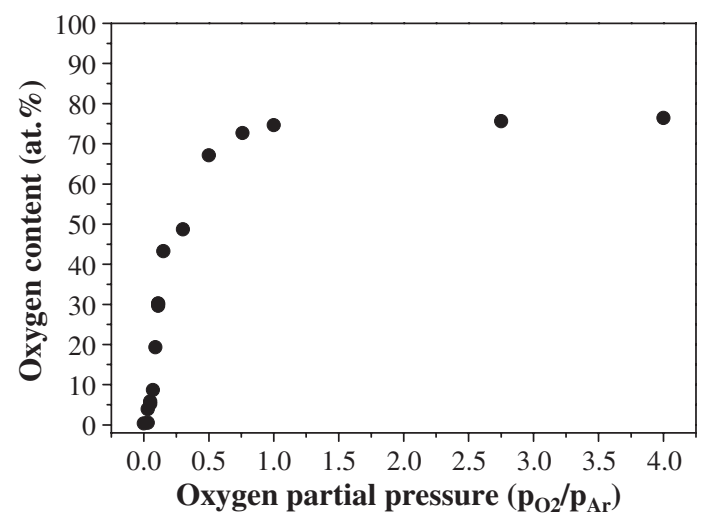

Fig. 1. Chemical composition determined by EPMA as a function of the oxygen partial pressure.

pure tungsten to the stoichiometric composition $\mathrm{WO}_{3}$ and to show their influence on the structure and mechanical properties of the coatings.

\section{Experimental details}

Tungsten oxide coatings were deposited by conventional DC reactive magnetron sputtering from a tungsten target with the dimensions $150 \times 150 \mathrm{~mm}^{2}$, where pure argon and oxygen (99.999\% purity) were used as sputtering and reactive gases, respectively. The substrate materials were polished high-speed (AISI M2) and stainless (AISI 304) steels, silicon wafer with the (111) orientation and glass. An ultimate vacuum pressure of $5 \times 10^{-4} \mathrm{~Pa}$ was reached before deposition, and the substrates surface were ion sputter cleaned with an ion gun by $\mathrm{Ar}^{+}$ bombardment (ion gun settings at $20 \mathrm{~A}, 40 \mathrm{~V}$ and substrates at $-70 \mathrm{~V})$.

The thickness of the coatings deposited on AISI M2 was evaluated by step profilometry with a Perthen apparatus. The deposition rate was calculated from the film thickness and the sputtering time.

The deposition of the coatings was carried at a total working pressure of $0.3 \mathrm{~Pa}$ using a target current density of $10 \mathrm{~mA}$ $\mathrm{cm}^{-2}$ and a floating substrate potential. The substrate temperature was close to $350{ }^{\circ} \mathrm{C}$. The substrates were placed at a distance of $65 \mathrm{~mm}$ from the target surface. The chemical composition of the coatings was evaluated by a Cameca SX-50 electron probe microanalysis (EPMA) apparatus, whereas their structure was analysed by X-ray diffraction (XRD) analysis using a Philips diffractometer with $\mathrm{Co} \mathrm{K} \alpha$ radiation.

The hardness and Young's modulus values of the coatings were evaluated by depth-sensing indentation technique using a Fischer Instruments-Fischerscope. The load was increased in 60 steps until an indentation load of $50 \mathrm{mN}$ was reached, and the same steps were taken for the unload segment. The testing procedure includes a correction of the experimental results for geometrical defects of the indenter tip, the thermal drift of the equipment, and the uncertainty in the initial contact, as described in detail elsewhere [7]. The values are the average of at least 8 indentations tests in two different zones and the error was given by standard deviation.
The adhesion/cohesion of the coatings was accessed by scratch-testing technique using a Revetest, CSM Instruments. The load was increased linearly from 0 up to $50 \mathrm{~N}$ using Rockwell C indenter tip with a radius of $200 \mu \mathrm{m}$, loading speed of $100 \mathrm{~N} / \mathrm{min}$ and scratch speed of $10 \mathrm{~mm} / \mathrm{min}$. The critical loads $\left(L_{\mathrm{c}}\right)$ values corresponding to the different failure mechanisms (adhesive/cohesive) were measured by analyzing the failures events in the scratch track by optical microscopy, for more details see [8].

\section{Results and discussion}

\subsection{Chemical composition and deposition rate}

The evolution of the oxygen content in the films as a function of the oxygen partial pressure $\left(p_{\mathrm{O}_{2}} / p_{\mathrm{Ar}}\right)$ in the deposition chamber is shown in Fig. 1. For low $p_{\mathrm{O}_{2}} / p_{\mathrm{Ar}}$ ratio values, a steep increase of the oxygen content in the coatings is observed until a saturation point, which corresponds to the formation of the stoichiometric compound $\mathrm{WO}_{3}$. This is reached for $p_{\mathrm{O}_{2}} / p_{\mathrm{Ar}}$ close to $1: 1$. Hence, by tuning the oxygen partial pressure between 0 and 1 , the full range of $\mathrm{W}-\mathrm{O}$ films with a chemical composition between pure tungsten $\left(\mathrm{W}_{100}\right)$ and trioxide tungsten $\left(\mathrm{W}_{25} \mathrm{O}_{75}\right)$ could be produced.

The deposition rate of tungsten oxide coatings was evaluated for different oxygen partial pressure, as presented in Fig. 2. Two different zones can be identified: initially, the deposition rate increases with increasing oxygen partial pressure up to a value of $p_{\mathrm{O}_{2}} / p_{\text {Ar }}$ close to $1: 1$. The incorporation of $\mathrm{O}$ in the $\mathrm{W}$ lattice leads to structural changes with the formation of new phases having different atomic arrangements. This gives rise to a lower specific molecular weight and consequently, to an increase in the coating volume and final coating thickness. A similar behaviour has been already confirmed for the $\mathrm{W}-\mathrm{O}$ system $[3,9], \mathrm{Cr}-\mathrm{O}$ system [10] and Mo-O system [11]. The two elements ( $\mathrm{Cr}$ and $\mathrm{Mo})$ belong to the same group in the periodic table as $\mathrm{W}$. For higher $p_{\mathrm{O}_{2}} / p_{\text {Ar }}$ value, the deposition rate decreases abruptly. This behaviour can be explained based on the occurrence of the socalled target poisoning by the reactive gas [6], which should be reached at $p_{\mathrm{O}_{2}} / p_{\mathrm{Ar}}>1$. Above this value, the formation of an

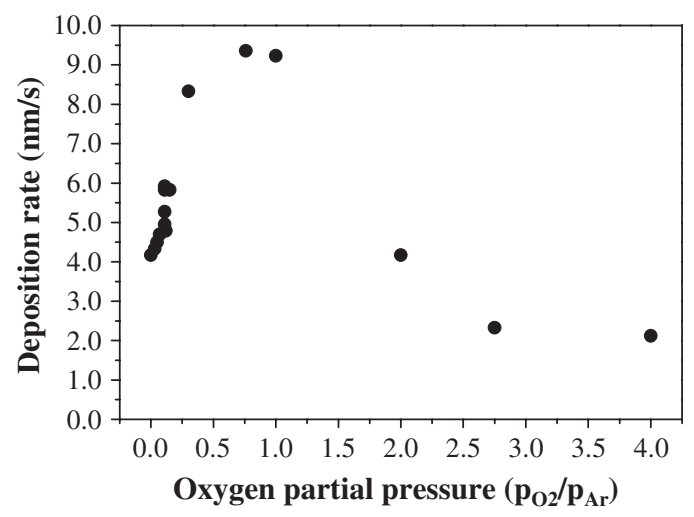

Fig. 2. Deposition rate of tungsten oxide as a function of oxygen partial pressure $\left(p_{\mathrm{O}_{2}} / p_{\mathrm{Ar}}\right)$. 


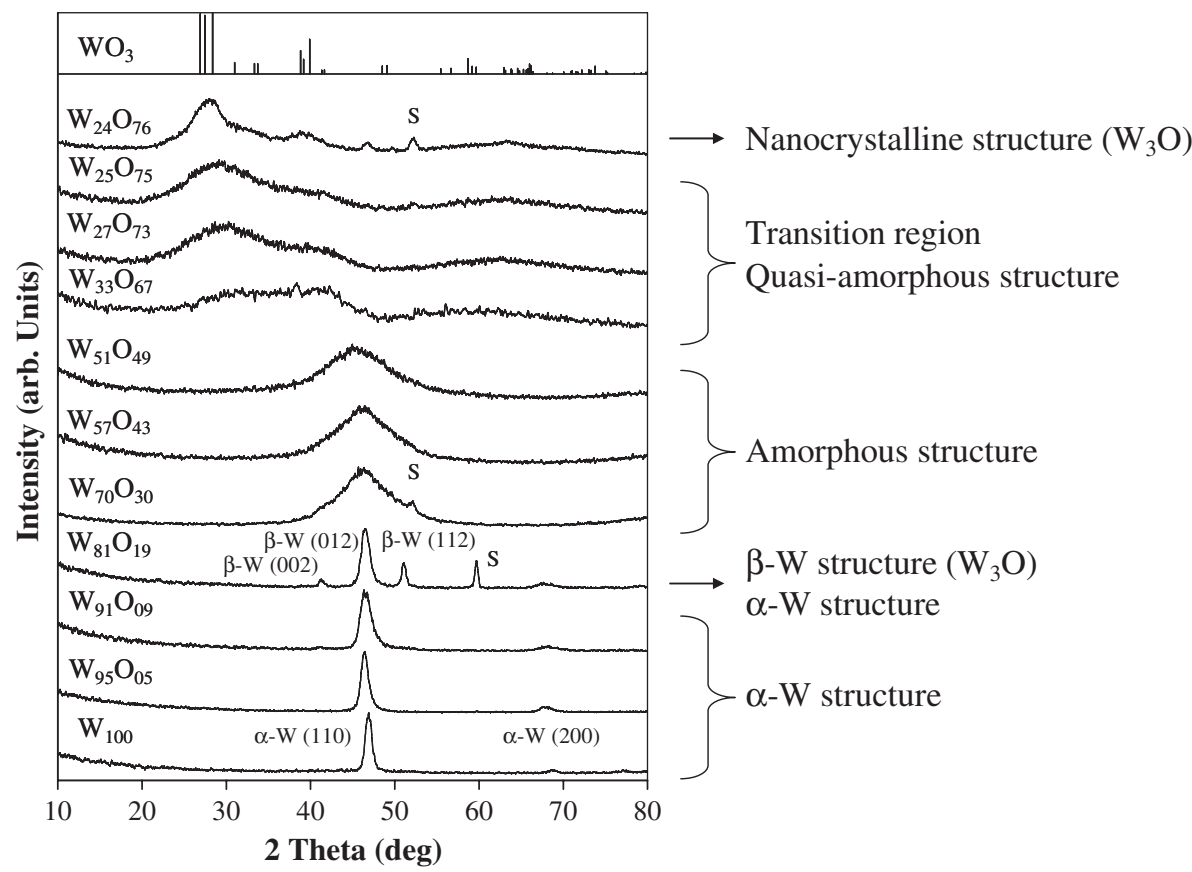

Fig. 3. XRD patterns of tungsten oxide coatings with different chemical compositions.

oxide layer at the target prevailed over their removal by the sputtering process and the compound regime was attained. The incorporation of the reactive gas in the target occurs at a sufficiently high rate to form a dielectric oxide layer covering completely the target surface.

\subsection{Structure}

The structural evolution of the $\mathrm{W}-\mathrm{O}$ thin films as a function of the oxygen content is shown in Fig. 3. The following structures are identified as a function of the oxygen content: i) $\mathrm{O}<30$ at. $\%$, crystalline structure constituted by the $\alpha-\mathrm{W}$ and $\beta$ $\mathrm{W}\left(\beta-\mathrm{W}_{3} \mathrm{O}\right)$ phases; ii) 30 at. $\%<\mathrm{O}<67$ at. $\%$, amorphisation of the coating structure, where only a broad peak centred at the $\alpha$ W (110) line is observed. With the increase of oxygen content the peak enlarges and becomes broader and less defined; iii) 67 at. $\%<0<75$ at. $\%$, quasi-amorphous structure, where ill-defined broad diffraction peaks are detected at different positions

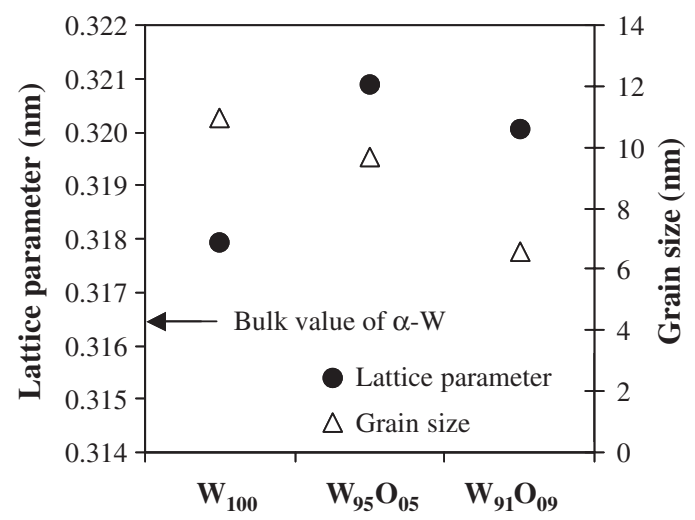

Fig. 4. Evolution of the lattice parameter and grain size of $\mathrm{W}_{100}, \mathrm{~W}_{95} \mathrm{O}_{05}$ and $\mathrm{W}_{91} \mathrm{O}_{09}$ coatings, calculated from the (110) $\alpha-\mathrm{W}$ line. from those corresponding to lower oxygen content; iv) $\mathrm{O}>75$ at.\%, nanocrystalline structure most probably due to the formation of the $\mathrm{WO}_{3}$ oxide. However, it should be noted that almost every form of $\mathrm{WO}_{3}$ existing in the JCPDS-ICDD database can be fitted to the peak positions, including the equilibrium stable form of the monoclinic structure.

The solubility of oxygen in tungsten in equilibrium conditions is very low [12]. Therefore, incorporation to the crystalline lattice of tungsten can only take place by a large distortion of the equilibrium structure through a non-equilibrium process technique such as sputtering. Detailed analyses of the XRD patterns of $\mathrm{W}-\mathrm{O}$ coatings with the b.c.c. $\alpha-\mathrm{W}$ phase shows that, with the increase in oxygen content, the position of the diffraction peak moves to the lower diffraction angles. This means that oxygen is allocated at the interstitial positions in the lattices, which leads to higher lattice parameters (see Fig. 4) and induces compressive residual stress. The residual stresses are responsible for the debonding and decohesion of the coatings, as exemplified in Fig. 5. This phenomenon occurs for a range of oxygen content lower

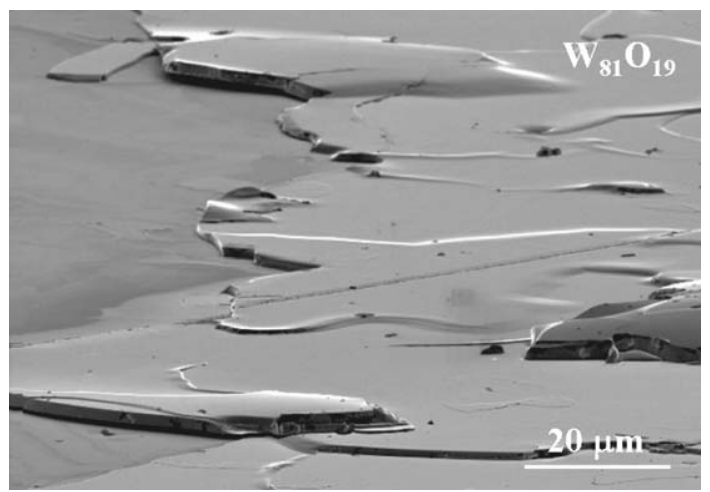

Fig. 5. Inclined plan-view SEM micrograph showing the debonding and decohesion of the $\mathrm{W}_{81} \mathrm{O}_{19}$ coating. 
than 20 at.\%. Other effect produced by the incorporation of the oxygen in the lattice of the b.c.c $\alpha-\mathrm{W}$ structure is the decreasing of the grain size, Fig. 4.

Above the maximum metastable solubility of $\mathrm{O}$ in $\mathrm{W}$ $\left(\mathrm{W}_{81} \mathrm{O}_{19}\right)$, the $\alpha-\mathrm{W}$ and $\beta-\mathrm{W}\left(\beta-\mathrm{W}_{3} \mathrm{O}\right)$ phases are detected by $\mathrm{XRD}$. The presence of the $\beta-\mathrm{W}$ phase is confirmed by successful fitting the 3 peaks within the range of $2 \theta$ between $40^{\circ}$ and $55^{\circ}$ to the plans (002), (012), and (112) of $\beta-\mathrm{W}_{3} \mathrm{O}$ [13]. The occurrence of the metastable $\beta$-W phase on $\mathrm{W}$ sputtered films is often referred in the literature [14], even when there is no intentional addition of $\mathrm{O}$ into $\mathrm{W}$, as occurs in the particular case of low adatom mobility depositions. Moreover, it has also been suggested that with deposition conditions of low discharge pressures (high adatom mobility) the presence of $\mathrm{O}$ stabilizes the $\beta-\mathrm{W}$ phase [15]. Therefore, it is not surprising that the presence of $\mathrm{O}$ in these coatings will promote the formation of the $\beta-\mathrm{W}$ phase. The evidence of the $\alpha-\mathrm{W}$ phase is not so straightforward because the main peak (110) overlaps the one from the plan (012) of the $\beta-\mathrm{W}$ phase. Consequently, other peaks from the $\alpha-\mathrm{W}$ phase have to be taken into account to confirm its existence. According to the ICDD standard value of $\alpha-\mathrm{W}$ [16], the plan (200) of $\alpha-\mathrm{W}$ occurs at a $2 \theta$ angle of $68.862^{\circ}$, and the detection of a diffraction line close to $2 \theta \approx 69^{\circ}$ reinforces the assumption of the presence of both phases in coatings within this oxygen range content.

The coatings with $\mathrm{O}$ contents in the range of 30 at. $\%$ to 67 at. $\%$ only show a broad peak centred at the (110) $\alpha$-W position, suggesting a low-range order in the films. With the increase of $\mathrm{O}$ content the peak becomes less defined with broader FWHM (full width half maximum) and lower intensity. In a previous work [17] concerning the deposition of $\mathrm{W}-\mathrm{Si}$ coatings, a similar trend was observed with the increase of Si alloying content. In that case, the developments of the structures were:

$\alpha-\mathrm{W} \rightarrow \alpha-\mathrm{W}+\beta-\mathrm{W} \rightarrow \beta-\mathrm{W}+$ amorphous

$\rightarrow$ amorphous.

It was also mentioned that the amorphous state for this type of coatings should present short range order where the atomic arrangement should be close to that shown in crystalline state. In analogy to $\mathrm{W}-\mathrm{O}$ coatings, the position of the XRD amorphous peak is at approximately the same diffraction angle than (110) or (210) plans of $\alpha-\mathrm{W}$ or $\beta-\mathrm{W}$, respectively. Furthermore, a similar reasoning may be applied to coatings with an oxygen content between 67 at. $\%$ and 75 at.\%, whose structure is still amorphous, but the most intense peak occurs at a $2 \theta$ position close to $30^{\circ}$, which overlaps the (011) plan of the monoclinic form of $\mathrm{WO}_{3}$. Keeping constant the increase in $\mathrm{O}$ content, the XRD pattern progressively changes its appearance, becoming more defined regarding the form of one of the $\mathrm{WO}_{3}$ phases. The peak with maximum intensity moves to the left, suggesting an increase in the lattice parameter. This should be in accordance with the structural change from $\mathrm{WO}_{2}$ to $\mathrm{WO}_{3}$ (in a monoclinic system) for which the increase of the $c$ axis from 5.6 to $7.7 \AA$ gives a necessary rise to the shift of the respective diffraction peaks for lower angles. In fact, the $\mathrm{W}_{27} \mathrm{O}_{73}$ coating shows an ill-defined structural feature that can be correlated to excess of oxygen in the $\mathrm{WO}_{2}$ [18] despite its chemical composition pointing to the $\mathrm{WO}_{3}$ phase. Concerning the $\mathrm{W}_{24} \mathrm{O}_{76}$ coating, the diffraction peaks of XRD pattern suggest a nanocrystalline structure. At the moment, it is difficult to state that it corresponds to the $\mathrm{WO}_{3}$ monoclinic (the equilibrium structure), since the ICDD patterns of $\mathrm{W}_{20} \mathrm{O}_{58}, \mathrm{~W}_{5} \mathrm{O}_{14}, \mathrm{WO}_{2.90}$, and others forms of $\mathrm{WO}_{3}$ (cubic, orthorhombic, triclinic) also have diffraction peaks in the same region as the $\mathrm{WO}_{3}$ monoclinic phase [19] shown in Fig. 3.

\subsection{Mechanical properties}

The mechanical properties of the coatings evaluated in this paper consisted of measuring the hardness $(H)$ and Young's modulus $(E)$ values as a function of their oxygen content, as shown in Fig. 6.

Four different regions of hardness and Young's modulus values have been identified and correlated to the coatings structure: (i) For lower oxygen contents, the coatings displayed the $\alpha-\mathrm{W}$ phase to which corresponds the highest $H$ values of $20-25 \mathrm{GPa}$. (ii) The increase of oxygen content up to 20 at. $\%$ resulted in the additional formation of the $\beta-\mathrm{W}\left(\mathrm{W}_{3} \mathrm{O}\right)$ phase or the amorphisation of the structure and a decrease of the hardness to intermediate values of $17 \mathrm{GPa}$, without any change in the $E$ value. The drop in the hardness of W-based coatings with the occurrence of the $\beta-\mathrm{W}$ phase was also detected before for $\mathrm{W}-\mathrm{Si}$ films [17], and in the study of the $\mathrm{W}-\mathrm{N}$ system [20]. Single $\mathrm{W}$ film showed a very high E value of $450 \mathrm{GPa}$, which drops significantly to $\approx 300 \mathrm{GPa}$ with the $\mathrm{O}$ additions, despite the approximately constant hardness. Such a trend allows to envisage a much better tribological behavior of $\mathrm{W}-\mathrm{O}$ coatings in relation to $\mathrm{W}$ (higher $H / E$ ratios) as suggested often in recent literature [21]. (iii) Coatings with an oxygen content up to 50 at.\% showed an amorphous structure, to which corresponds a

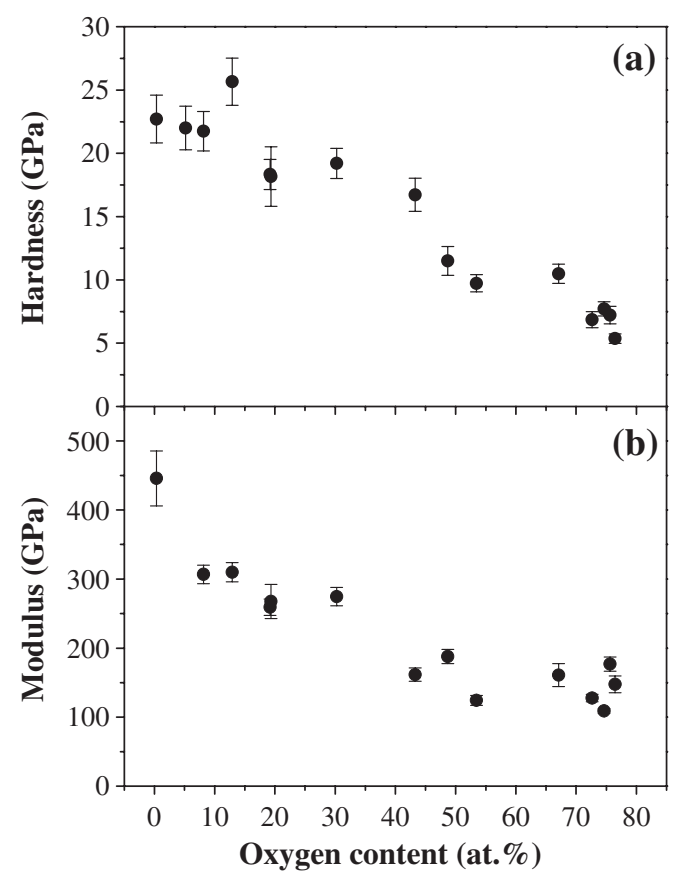

Fig. 6. Hardness (a) and Young's modulus (b) values of tungsten oxide as a function of the oxygen content in the coatings. 
further decrease of the hardness and Young's modulus values to $10 \mathrm{GPa}$ and $150 \mathrm{GPa}$, respectively. Recent studies [22,23] showed that the formation of amorphous structures in W-based films, particularly from the $\mathrm{W}-\mathrm{Si}-\mathrm{N}$ system, systematically led to lower hardness values compared to those measured in crystalline films even for similar chemical compositions. (iv) Finally, for the highest oxygen content, with stoichiometry very close to $\mathrm{WO}_{3}$, the coatings displayed a quasi-amorphous or nanocrystalline structure and the hardness and modulus values are rather constant at about $7 \mathrm{GPa}$ and $150 \mathrm{GPa}$, respectively.

The results obtained can be compared to the ones of Lugscheider et al. [4]. These authors found hardness in the range of 13 and $28 \mathrm{GPa}$ (measured by nanoindentation). Nevertheless, the correlation is difficult since there is no mention to quantitative composition of the coatings, being the hardness results shown as a function of the oxygen/argon ratio in the chamber. However, they showed the same decreasing trend for hardness with $\mathrm{O}_{2}$ enrichment in the sputtering atmosphere. It should be noted that the highest hardness values were obtained, by these authors, using a negative applied bias, in contrast to the grounded depositions conditions used in this work. In another recent work [24], references to the hardness of $\mathrm{W}$ and $\mathrm{WO}_{3}$ of 14 and $4 \mathrm{GPa}$, respectively, were given, which is in good accordance with the results presented in this paper.

\subsection{Adhesion/cohesion}

The adhesion/cohesion of the coatings to the substrate is an important subject to consider regarding their mechanical applications. A suitable procedure to measure the adhesion/ cohesion values consists of using a scratch-test apparatus to calculate the critical loads $L_{\mathrm{c} 1}$ and $L_{\mathrm{c} 2}$. These critical loads are defined as the first cohesive and adhesive failures, respectively. The cohesive $L_{\mathrm{c} 1}$ values are difficult to quantify because the coatings either do not exhibit such failure or the values are very close to the adhesive ones $\left(L_{\mathrm{c} 2}\right)$. Thus, Fig. 7 displays only the $L_{\mathrm{c} 2}$ critical load values of $\mathrm{W}-\mathrm{O}$ coatings as a function of the oxygen content.

Two categories of results can be assessed: (i) for low oxygen contents (Zone I from Fig. 7), the coatings exhibited frequently delamination, hinder the evaluation of $L_{\mathrm{c}}$ values. In a posterior

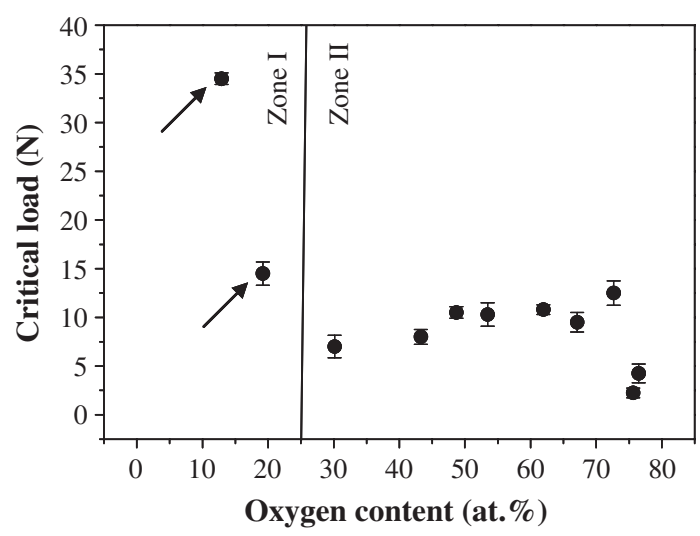

Fig. 7. Critical load of tungsten oxide as a function of the oxygen content in the coatings. The arrowed coating was deposited with a tungsten inter layer. series of depositions, an interlayer was interposed between the coating and the substrate to improve adhesion, which gave rise to the $L_{\mathrm{c} 2}$ values shown. (ii) For higher oxygen content, all coatings presented very low values of critical loads $(<15 \mathrm{~N})$ being observed only a slightly increase from 7 to $13 \mathrm{~N}$ while increasing $\mathrm{O}$ content up to 73 at.\%. A sudden reduction in $L_{\mathrm{c} 2}$ was achieved for films with $\mathrm{O} \approx 5$ at. $\%$, for which values lower than $5 \mathrm{~N}$ were registered. The difference of $L_{\mathrm{c} 2}$ values can be explained considering the variation of the coating thickness (see the deposition rate in Fig. 2), which follows exactly the same trend: It increased until an oxygen content of 73 at. $\%$ and then decreased abruptly. These results are in line with the wellknown fact that the adhesive $L_{\mathrm{c} 2}$ values increase with increasing coating thickness [25].

To improve the adhesion of the coatings several methods are possible to be applied, namely: promote an efficient etching of the substrate samples, using negative substrate bias, heating the substrate, using ion gun bombardment or deposit an interlayer [25]. In this study, two coatings were deposited with an interlayer of pure $\mathrm{W}$ to improve the adhesion as shown in Fig. 7. The high values demonstrate clearly that an improvement of the adhesion can be reached. However, even this solution might not be enough for using these coatings in most industrial applications.

\section{Conclusions}

The results presented in this work are part of a preliminary study to understand the $\mathrm{W}-\mathrm{O}-\mathrm{N}$ system.

It has been shown that it is possible to deposit films by $\mathrm{DC}$ reactive magnetron sputtering with chemical compositions ranging from pure $\mathrm{W}$ to the stoichiometric $\mathrm{WO}_{3}$ phase, which was reached for an oxygen partial pressure $\left(p_{\mathrm{O}_{2}} / p_{\mathrm{Ar}}\right)$ close to $1: 1$. Two regions were defined for the deposition rate: i) before reaching the stoichiometric composition, the deposition rate increases linearly with the increasing of the oxygen partial pressure; and ii) close to the stoichiometry, the deposition rate strongly decreases due to the poisoning effect of the target. XRD patterns of the films showed four distinct zones: i) crystalline $(\mathrm{O}<30$ at. $\%)$; ii) amorphous (30 at. $\%<\mathrm{O}<67$ at. $\%$ ); iii) transition region with a quasi-amorphous structure (67 at. $\%<\mathrm{O}<75$ at. $\%)$; and iv) nanocrystalline ( $\mathrm{O}>75$ at. $\%)$. The hardness decreased monotonically with increase of $\mathrm{O}$ content from $\approx 23 \mathrm{GPa}$ for pure $\mathrm{W}$ down to $\approx 7 \mathrm{GPa}$ for $\mathrm{WO}_{3}$ films. $\mathrm{A}$ similar behaviour was observed for the Young's modulus, which varied from $450 \mathrm{GPa}$ to $150 \mathrm{GPa}$. The coatings displayed a low adhesion to the steel substrate $\left(L_{\mathrm{c}}<15 \mathrm{~N}\right)$ because the depositions were carried out intentionally without an adhesion layer.

\section{Acknowledgements}

The work described in this paper was supported by the European Union through the NMP3-CT-2003-505948 project "HARDECOAT". The authors would like to acknowledge Prof. J. Th. M. De Hosson from the University of Groningen, The Netherlands for the use of the electron microscopy 
facilities. The author Parreira acknowledges "Fundação para a Ciência e Tecnologia" for the Ph.D. Scholarship grant SFRH/ $\mathrm{BD} / 16528 / 2004$.

\section{References}

[1] C.G. Granqvist, Handbook of Inorganic Electrochromic Materials, Elsevier, Amsterdam, 1995

[2] C.-J. Jin, T. Yamazaki, Y. Shirai, T. Yoshizawa, T. Kikuta, N. Nakatani, H. Takeda, Thin Solid Films 474 (2005) 255.

[3] A. Yamamoto, Y. Abe, M. Kawamura, K. Sasaki, Vacuum 66 (2002) 269.

[4] E. Lugscheider, S. Bärwulf, C. Barimani, Surf. Coat. Technol. 120/121 (1999) 458.

[5] S.C. Moulzolf, R.J. Lad, S. Diang, Sens. Actuators, B, Chem. 77 (2001) 375.

[6] I. Safi, Surf. Coat. Technol. 127 (2000) 203.

[7] J.M. Antunes, A. Cavaleiro, L.F. Menezes, M.I. Simões, J.V. Fernandes, Surf. Coat. Technol. 149 (2002) 27.

[8] R. Jacobs, J. Meneve, G. Dyson, D.G. Teer, N.M. Jennett, P. Harris, J.V. Stebut, C. Comte, P. Feuchter, A. Cavaleiro, H. Ronkainen, K. Holmberg, U. Berk, G. Reiners, C.D. Ingelbrecht, Surf. Coat. Technol. 174/175 (2003) 1008.

[9] H. Kaneko, F. Nagao, K. Miyake, J. Appl. Phys. 63 (1988) 510.

[10] U. Rothhaar, H. Oechsner, Surf. Coat. Technol. 59 (1993) 183.

[11] M. Kharrazi, A. Azens, L. Kullman, C.G. Granqvist, Thin Solid Films 295 (1997) 117
[12] T.B. Massalski, Binary Alloy Phase Diagrams, ASM International, Materials Park, OH, 1990.

[13] Powder Diffraction File, Joint Committee on Power Diffraction Standards, ASTM, Philadelphia, PA, 2000, Card 41-1230.

[14] G.S. Chen, H.S. Tian, C.K. Lin, G.-S. Chen, H.Y. Lee, J. Vac. Sci Technol., A, Vac. Surf. Films 22 (2004) 281.

[15] É. Hegedüs, J. Neugebauer, M. Mészáros, Int. J. Refract. Met. Hard Mater. 16 (1998) 31

[16] Powder Diffraction File, Joint Committee on Power Diffraction Standards, ASTM, Philadelphia, PA, 2000, Card 04-0806.

[17] A. Cavaleiro, B. Trindade, M.T. Vieira, in: A. Cavaleiro, J.T. De Hosson (Eds.), Nanostructured Coatings, Kluwer Publications, 2005.

[18] Powder Diffraction File, Joint Committee on Power Diffraction Standards, ASTM, Philadelphia, PA, 2000, Card 71-0614.

[19] Powder Diffraction File, Joint Committee on Power Diffraction Standards, ASTM, Philadelphia, PA, 2000, Card 83-0950.

[20] N.M.G. Parreira, N.J.M. Carvalho, F. Vaz, A. Cavaleiro, Surf. Coat. Technol. (in press).

[21] J. Musil, F. Kunc, H. Zeman, H. Poláková, Surf. Coat. Technol. 154 (2002) 304.

[22] A. Cavaleiro, C. Louro, Vacuum 64 (2002) 211.

[23] A. Cavaleiro, A.P. Marques, J.V. Fernandes, N.J.M. Carvalho, J.T. De Hosson, J. Mater. Res. 20 (5) (2005) 1356.

[24] L. Maillé, C. Sant, P. Aubert, P. Garnier, Thin Solid Films 479 (2005) 201.

[25] R.F. Bunshah, Handbook of Hard Coatings, Noyes Publications, New Jersey, 2001. 